\title{
Analysis of WRF-Simulated Diurnal Boundary Layer Winds in Eastern China Using a Simple 1D Model
}

\author{
YU DU \\ Laboratory for Climate and Ocean-Atmosphere Studies, Department of Atmospheric and Oceanic Sciences, \\ School of Physics, Peking University, Beijing, China, and National Center for \\ Atmospheric Research,* Boulder, Colorado \\ RICHARD ROTUNNO \\ National Center for Atmospheric Research,* Boulder, Colorado \\ QINGHONG ZHANG \\ Laboratory for Climate and Ocean-Atmosphere Studies, Department of Atmospheric and \\ Oceanic Sciences, School of Physics, Peking University, Beijing, China
}

(Manuscript received 30 June 2014, in final form 27 August 2014)

\begin{abstract}
The low-level diurnal winds for different locations of eastern China are documented using the June 2006-11 hourly model data simulated with the Weather Research and Forecasting (WRF) mesoscale model with a 9-km horizontal resolution. A simple 1D model, including both diurnal thermal forcing and diurnally varying boundary layer friction, is found to explain important features of the WRF-simulated diurnal boundary layer winds in eastern China. For example, in northeastern China, at a similar latitude, the maximum velocity parallel to the coastline at a longitude over the ocean occurs earlier than the maximum velocity parallel to the inland chain of coastline-parallel mountains at a longitude over land. This difference can be identified with the well-known Blackadar effect over the land. Off the eastern coast of China, the diurnal winds for different latitudes over the ocean vary in both phase and amplitude, consistent with expectations based on the simple $1 \mathrm{D}$ model.
\end{abstract}

\section{Introduction}

Diurnal variation of the boundary layer winds is a prominent feature of coastal regions, where land-sea temperature gradients exist, or near mountains, where slope flows are prevalent (Rotunno 1983; Stensrud 1996; Rife et al. 2010). A common feature of these winds is a nocturnal low-level jet (LLJ) that frequently occurs in those regions, such as the Great Plains LLJ, east of the Rocky Mountains (Bonner 1968; Whiteman et al. 1997),

\footnotetext{
* The National Center for Atmospheric Research is sponsored by the National Science Foundation.
}

Corresponding author address: Dr. Richard Rotunno, National Center for Atmospheric Research, P.O. Box 3000, Boulder, CO 80307-3000.

E-mail: rotunno@ucar.edu the California coastal jet (Burk and Thompson 1996), and the Chilean coastal jet (Jiang et al. 2010). Recent studies using observational data (Du et al. 2012; Wei et al. 2013), reanalysis data (Wang et al. 2013; Liu et al. 2012), and numerical simulations (Rife et al. 2010; Du et al. 2014) show that LLJs in China also tend to occur over analogous physiographic regions exhibiting pronounced diurnal variations with maxima at night or in the early morning hours.

Diurnal thermal forcing over coastal or mountain areas is a popular explanation for the occurrence and diurnal variation of the $L L J$, as for example proposed by Holton (1967). Many subsequent studies (Bonner and Paegle 1970; Paegle and Rasch 1973; Jiang et al. 2007; Parish and Oolman 2010) represented diurnal thermal forcing through a diurnally varying geostrophic wind or pressure gradient that we will refer to herein as the "Holton" mechanism. Colle and Novak (2010) found 
that the warm-season, southerly New York Bight jet off the northern New Jersey coast peaks at 1900 LST and suggested that is associated with the diurnally varying cross-coast pressure gradient. Following this idea, Drobinski et al. (2011) developed the linear theory of the sea breeze in an alongshore thermal wind (to replicate warm-season conditions) and found that the daytime enhanced across-coast wind (i.e., the sea breeze) exhibits a clockwise rotation to along coast with a maximum at 1800 LST. However, Zhang et al. (2006) documented that $90 \%$ of the LLJs well inland from the coast at similar latitudes to New Jersey occur between 0000 and 0600 LST. Yu et al. (2009) suggested that the diurnal wind variation in wind direction over the coastal (mountain) regions of China is closely associated with the land-sea (mountain-valley) breezes.

Over land, the inertial oscillation due to the diurnal variation of boundary layer friction proposed by Blackadar (1957) plays an important role in the diurnal variation of LLJs (Jiang et al. 2007; Parish and Oolman 2010). The observed nocturnal wind maxima are a result of the inertial oscillation of the ageostrophic wind triggered by the sudden decay of eddy viscosity after sunset. Du et al. (2012) found from wind-profiler observations that boundary layer jets (BLJs) in Shanghai (Fig. 1b) have a diurnal cycle with a maximum wind speed at night and in the early morning with veering during this period similar to that expected from an inertial oscillation. Du et al. (2014) analyzed the momentum budgets from long-term high-resolution mesoscale numerical simulations and suggested that vertical mixing in the boundary layer during the day and an inertial oscillation at night are significant processes for diurnal variations of BLJs in China. Wei et al. (2013) applied the Hilbert-Huang transform technique (Huang and Shen 2005) to demonstrate that LLJs in Shanghai, China (Fig. 1b), have a cycle of $23 \mathrm{~h}$, which is the period of the inertial oscillation at that location.

Du and Rotunno (2014) using a simple analytical 1D model analyzed the roles of the Holton and Blackadar mechanisms in the diurnally varying LLJ over the Great Plains of the United States and its dependence on latitude. The simple model describes a diurnal wind pattern that should vary with latitude and/or time variation in surface friction (e.g., constant friction coefficient over the ocean; diurnally varying friction coefficient over land). Rotunno (1983) deduced from linear theory that land-sea breezes should, in the absence of dissipative processes, have very different diurnal patterns comparing latitudes greater than $30^{\circ} \mathrm{N}$ with latitudes less than $30^{\circ} \mathrm{N}$.

In the present study, we examine the lower-tropospheric diurnal winds at different locations across eastern China by comparing results from the Du et al. (2014) mesoscale model dataset (hereafter the Du model data) with output from the simplified Du and Rotunno (2014) 1D model (hereafter the Du-Rotunno 1D model). The Du model data and the Du-Rotunno 1D model are reviewed in section 2 . In section 3 , we analyze different diurnal winds at different locations of eastern China with the Du model data. In section 4, the Du-Rotunno 1D model is applied to explain the differences in these diurnal winds and the underlying physical reasons for them. The final section summarizes our results.

\section{Data and model}

In this section, the hourly Weather Research and Forecasting (WRF) Model dataset established by Du et al. (2014) and a simple analytical 1D model developed by Du and Rotunno (2014) are briefly reviewed.

\section{a. Review of the Du model data}

Du et al. (2014) used the high-resolution nonhydrostatic mesoscale Advanced Research version of WRF (ARW; Skamarock and Klemp 2008) to create hourly outputs from daily simulations of the atmosphere over China during the early summer (May-July from 2006 to 2011) with a horizontal grid spacing of $9 \mathrm{~km}$ and with 40 vertical levels. After being evaluated against observations, the dataset was used to study the spatial distribution of LLJs in China. The detailed model configuration and procedure are given in Du et al. (2014). They found that BLJs frequently occur over coastal areas or near mountains [Fig. 5 of Du et al. (2014)] and show nocturnal maxima.

Figure 1 shows the horizontal distribution of the diurnal cycle of the perturbation wind vectors and diurnalmean wind vectors at $950 \mathrm{hPa}$ for June, averaged from 2006 to 2011 with the Du model data. The diurnal signal (Fig. 1a) is significant over land and near the coastline and becomes weaker at low latitudes and over the ocean far away from the coastline. The amplitude and phase of the diurnal variations are distinctly different depending on location. Four locations are chosen here for study of the diurnal winds (Fig. 1b): location A is over flat terrain but near the roughly north-south ridge of the Taihang Mountains, location B is nearly at the same latitude as A but is situated over the ocean near the coast, and locations $\mathrm{C}$ and $\mathrm{D}$ are also sites over the coastal ocean but at lower latitudes.

The diurnal-mean wind directions (Fig. 1b) are roughly parallel to either the coastline or the mountains. Therefore, to apply our 1D model with a specified pressure gradient only in the $x$ direction, the coordinates $(x, y)$ for each location are rotated to the local coordinates $\left(x^{\prime}, y^{\prime}\right)$, with the $y^{\prime}$ axis perpendicular to the 

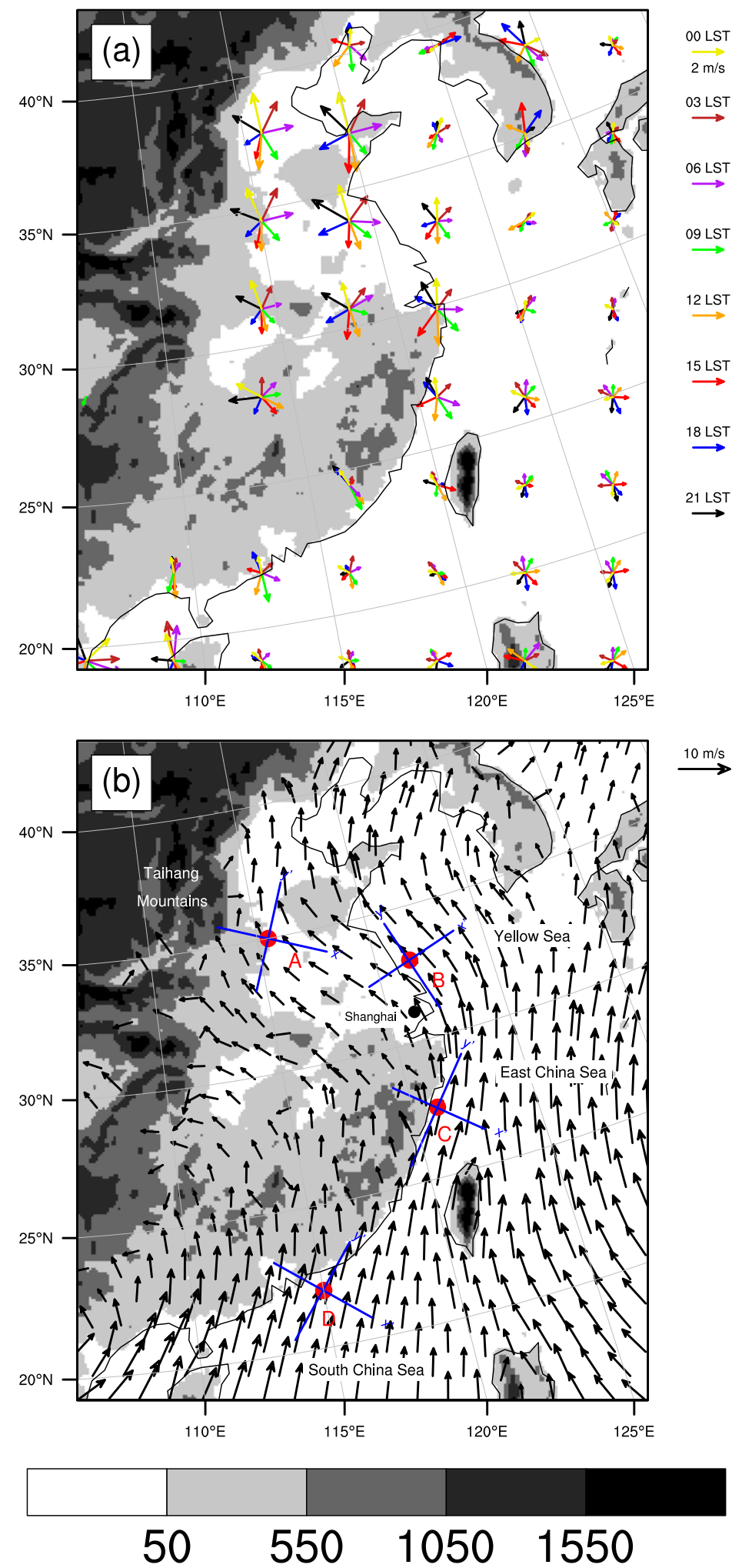

FIG. 1. Horizontal distribution of (a) diurnal cycle of the perturbation wind vectors at 3-h intervals and (b) diurnal-mean wind vectors at the $950-\mathrm{hPa}$ height for June from 2006 to 2011 with terrain height (shading; $\mathrm{m}$ ) and locations $\mathrm{A}, \mathrm{B}, \mathrm{C}$, and D with the local rotated Cartesian coordinates used in the present analysis. 
mean pressure gradient. This direction turns out to be roughly parallel to the coastlines or mountains or approximately in the prevailing wind direction. Therefore,

$$
\begin{aligned}
& u^{\prime}=u \cos \varphi-v \sin \varphi \quad \text { and } \\
& v^{\prime}=u \sin \varphi+v \cos \varphi,
\end{aligned}
$$

where $u^{\prime}$ and $v^{\prime}$ are the wind speeds along the $x^{\prime}$ and $y^{\prime}$ axes, respectively, and $\varphi$ is the angle between the $y^{\prime}$ axis and the $y$ axis. For brevity, we use $(u, v)$ and $(x, y)$ instead of $\left(u^{\prime}, v^{\prime}\right)$ and $\left(x^{\prime}, y^{\prime}\right)$ hereafter.

To investigate the mechanisms for the diurnal winds and further compare the results to the simple 1D model, a momentum budget analysis is also done as in $\mathrm{Du}$ et al. (2014). The horizontal momentum equation in local coordinates can be written as

$$
\begin{aligned}
& \frac{\partial u}{\partial t}=\left(-u \frac{\partial u}{\partial x}-v \frac{\partial u}{\partial y}\right)-\frac{1}{\rho} \frac{\partial P}{\partial x}+f v+F_{x} \quad \text { and } \\
& \frac{\partial v}{\partial t}=\left(-u \frac{\partial v}{\partial x}-v \frac{\partial v}{\partial y}\right)-\frac{1}{\rho} \frac{\partial P}{\partial y}-f u+F_{y},
\end{aligned}
$$

where $P$ is the pressure, $\rho$ is the density of air, and $f$ is the Coriolis parameter. Equations (2.3) and (2.4) state that the local acceleration equals the sum of horizontal advection (ADV), pressure gradient force (PGF), Coriolis force $(\mathrm{CF})$, and friction (RES). RES comprises friction, vertical advection, and model error; based on the analysis of Du et al. (2014), the frictional force is the dominant term in RES.

\section{b. Review of the Du-Rotunno $1 D$ model}

Following early studies of the sea breeze (Haurwitz 1947; Schmidt 1947), Du and Rotunno (2014) studied the following one-dimension linear equations of motion for frictional flow on an $f$ plane:

$$
\begin{gathered}
\frac{\partial u}{\partial t}-f v=-\frac{1}{\rho} \frac{\partial P}{\partial x}-\alpha u, \\
\frac{\partial v}{\partial t}+f u=-\alpha v, \quad \text { and } \\
-\frac{1}{\rho} \frac{\partial P}{\partial x}=\bar{F}+\hat{F} \cos \omega t
\end{gathered}
$$

where $\alpha$ is the diurnally varying frictional coefficient and $\omega$ is the diurnal frequency $\left(=2 \pi\right.$ day $\left.^{-1}\right)$. The pressure gradient in the $x$ direction is composed of a mean $(\bar{F})$ and a diurnally varying $(\hat{F} \cos \omega t)$ contribution. After nondimensionalizing the equations, analytical solutions were obtained for 1) constant friction with diurnally varying pressure gradient (Holton), 2) diurnally varying friction with a time-independent pressure gradient (Blackadar), and 3) the combination of both (Du and Rotunno 2014).

\section{c. Numerical solution of the simple model}

$\mathrm{Du}$ and Rotunno (2014) considered $\alpha$ to be a step function of time (large in the daytime, small at night) to obtain a simple analytical solution. ${ }^{1}$ In this paper, in order to make the simple model somewhat more flexible, we set $\alpha=\alpha_{0}(1+\sin \omega t)$, where $\alpha_{0}$ is daily-mean frictional coefficient. A numerical method is used to achieve the diurnally periodic solution to (2.5)-(2.7): that is,

$u^{t+\Delta t}=u^{t}+\Delta t\left(f v^{t}+\bar{F}+\hat{F} \cos \omega t-\alpha u^{t}\right) \quad$ and

$v^{t+\Delta t}=v^{t}+\Delta t\left(-f u^{t}-\alpha v^{t}\right)$,

where the superscript $t$ refers to time.

Starting from a state of rest, the numerical model is integrated forward long enough for the decay of transients and the emergence of the diurnally periodic solution, which was achieved after 6 days; solution-technique accuracy was verified against the Du and Rotunno (2014) analytical solutions with $\alpha$ a piecewise constant.

\section{Diurnal winds at different locations}

Figures $2 \mathrm{a}-\mathrm{d}$ show diurnal variations of the $950-\mathrm{hPa}$ local $u$ - and $v$-wind components at locations A, B, C, and D (Fig. 1b) from the Du model data. To reduce representativeness errors, data from $9 \times 9$ grid points centered on each location are averaged together. However, the results are not sensitive to the number of grid points used for averaging at these four locations (relatively flat terrain). Averaging over fewer points produces a bit more noise, but the general diurnal variations are consistent with the results using an average over $9 \times 9$ grid points. Figure 3 has a comparison of the interannual variability, which will be discussed below.

For location A over the land east of the Taihang Mountains, the maximum of $v\left(v_{\max }\right)$ occurs around 0200 LST (Fig. 2a), which is similar to the Great Plains LLJ of the United States (Parish and Oolman 2010; Jiang et al. 2007; Du and Rotunno 2014). Associated with the mountain-valley thermal circulation, the pressure gradient in the $x$ direction $^{2}$ (i.e., perpendicular to the mountains; blue line in Fig. 4a) exhibits a pronounced

\footnotetext{
${ }^{1}$ It has come to our attention that a similar solution was obtained in Thorpe and Guymer (1977).

${ }^{2}-(1 / \rho)(\partial P / \partial x)$ is calculated from $-\partial \Phi / \partial x$, where $\Phi$ is the geopotential.
} 

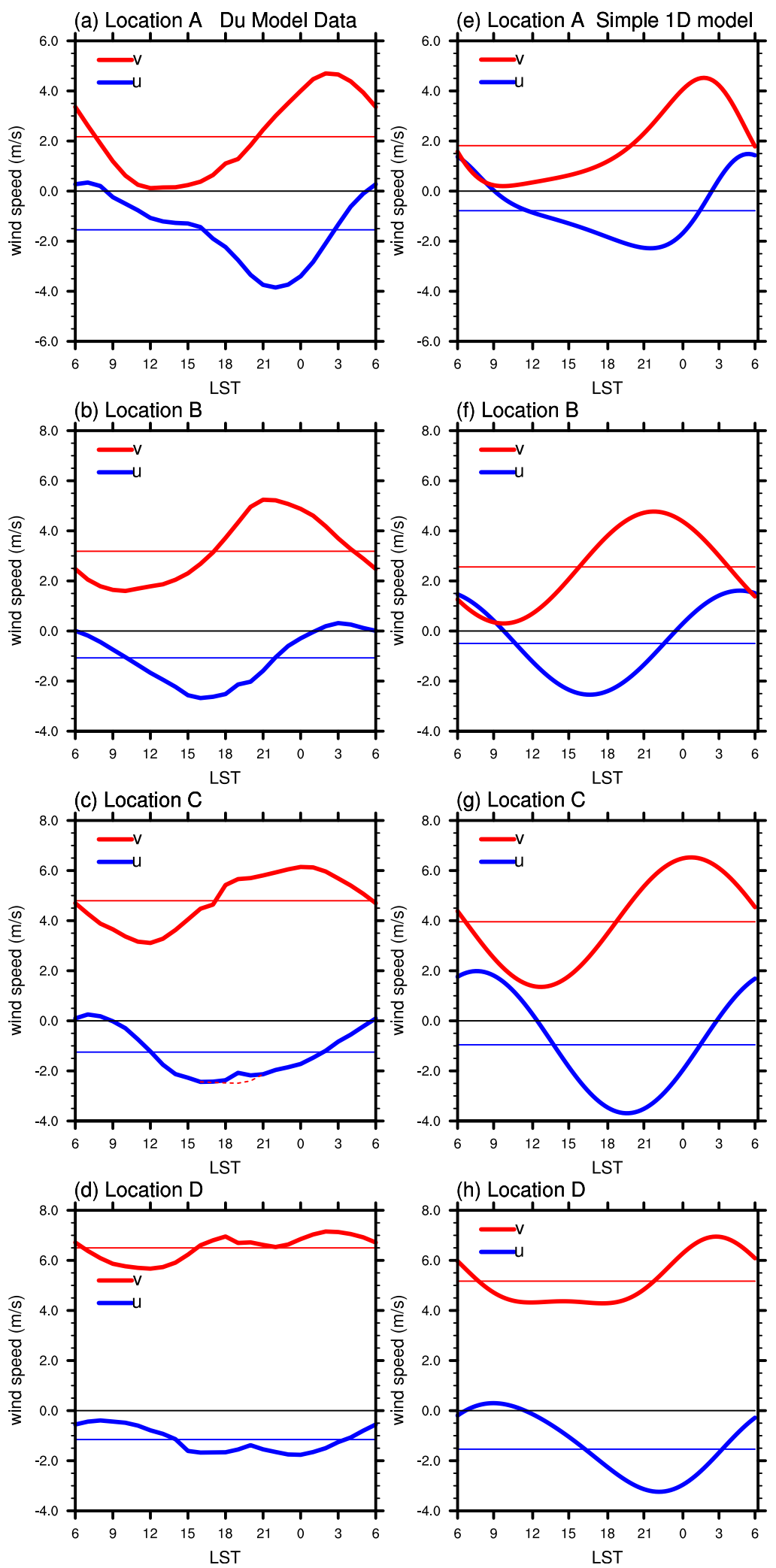

FIG. 2. Diurnal variations of mean 950-hPa local $u$ - and $v$-wind components at locations A, B, C, and D from (a)-(d) the Du model data and (e)-(g) the simple 1D model with mean values indicated by the thin solid lines. A red dashed line is added in (c) to give a more reliable estimate of the time of $u_{\min }$. 
(a) Location A

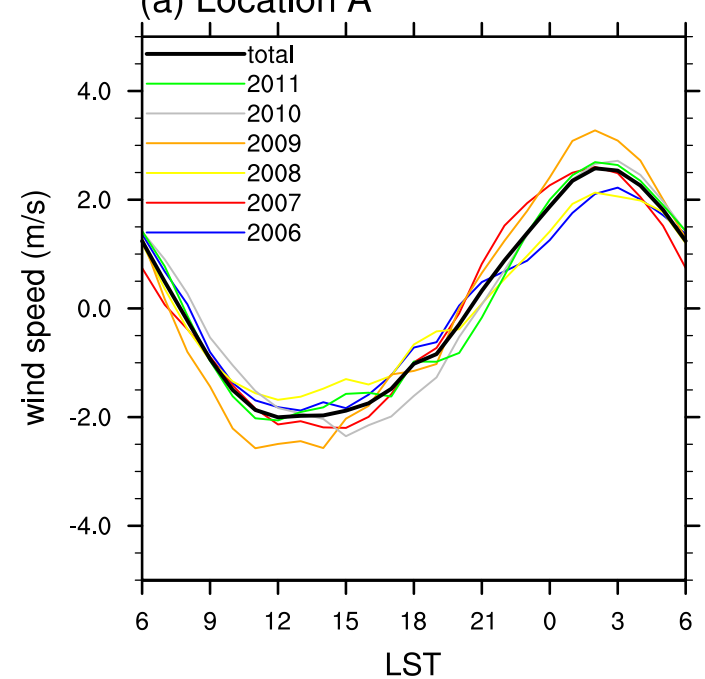

(c) Location C

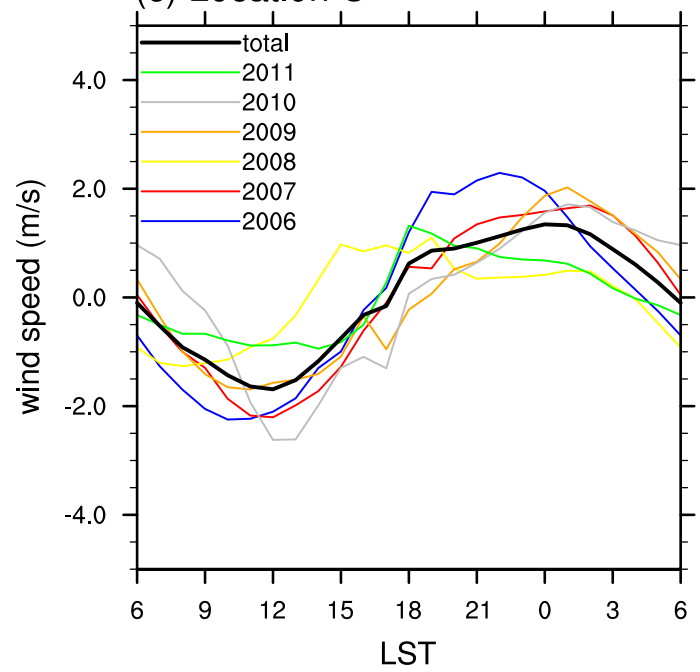

(b) Location $\mathrm{B}$

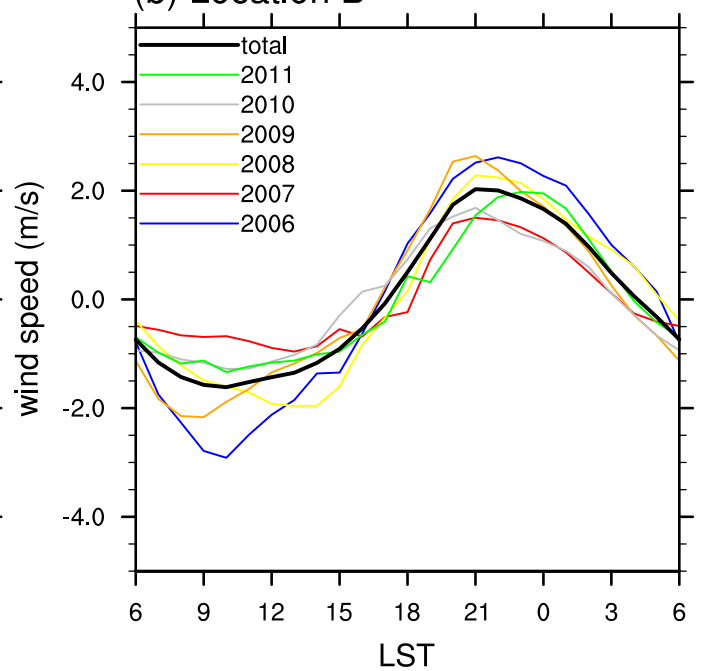

(d) Location D

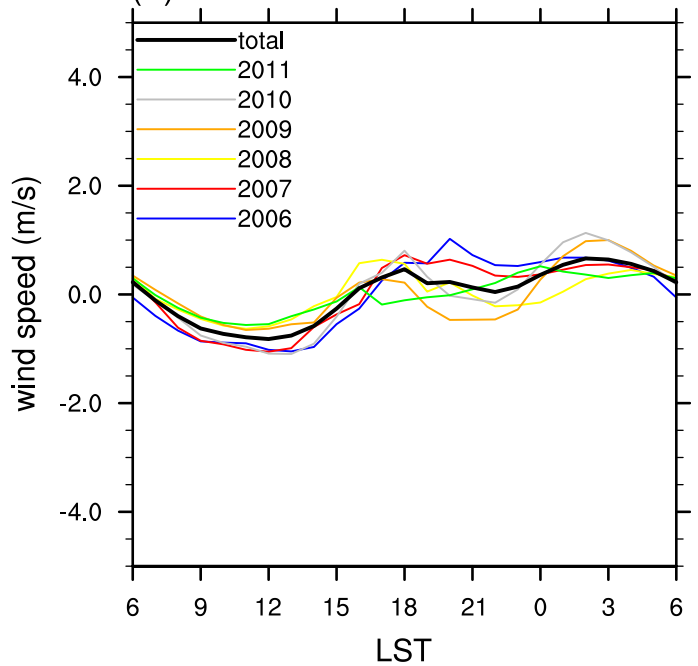

FIG. 3. Diurnal variations of year-to-year-mean and total-mean 950-hPa local $u$ - and $v$-wind components at locations (a) A, (b) B, (c) C, and (d) D from the Du model data from 2006 to 2011.

diurnal cycle with a minimum around 1800 LST (approximate sunset), whereas the pressure gradient in $y$ direction (i.e., parallel to the mountains; blue line in Fig. 4b) is weak. The momentum-budget analysis in Fig. 4a shows that the friction term (yellow line) in the $x$ direction is larger during the daytime than at night, which is consistent with the theory proposed by Blackadar (1957) that strong vertical mixing during the daytime decays after sunset. Note that the friction term in the $y$ direction (yellow line in Fig. 4b) is small during the daytime because $v$ is small.

Location B is located off the coast over the Yellow Sea (Fig. 1b) and is at a similar latitude to that of location A. Figure $2 \mathrm{~b}$ shows that at location $\mathrm{B}, v_{\max }$ occurs at 2100 LST and $u_{\min }$ occurs at 1600 LST. Comparison of these extrema at location B with those at location A (cf.
Figs. 2a and 2b) indicate their earlier occurrence at location $\mathrm{B}$ than at location $\mathrm{A}$ even though the diurnal variation of the pressure gradient in the $x$ direction reaches a minimum around 1800 LST (sunset) at both locations A and B (cf. blue lines in Fig. 4a and Fig. 5a). Note that at location $\mathrm{B}$ the diurnal variation of the pressure gradient is due to the land-sea thermal contrast.

Both locations $\mathrm{B}$ and $\mathrm{C}$ are over the ocean at a similar longitude (Fig. 1b), but location $\mathrm{B}$ is at a higher latitude $\left(>30^{\circ} \mathrm{N}\right)$ than location $\mathrm{C}\left(<30^{\circ} \mathrm{N}\right)$. Figure $2 \mathrm{c}$ shows that at location $\mathrm{C} u_{\max }$ and $v_{\max }$ occur about $4 \mathrm{~h}$ later than they do at location $\mathrm{B}$, even though the diurnal variation of the respective pressure gradients in the $x$ direction for locations B and C are similar (cf. blue lines in Figs. 5a and $6 \mathrm{a}$ ). Note that at location $\mathrm{C}, v_{\max }$ occurs after midnight (0100 LST) (Fig. 2c). The indentation near 
(a) Location A from the Du model Data

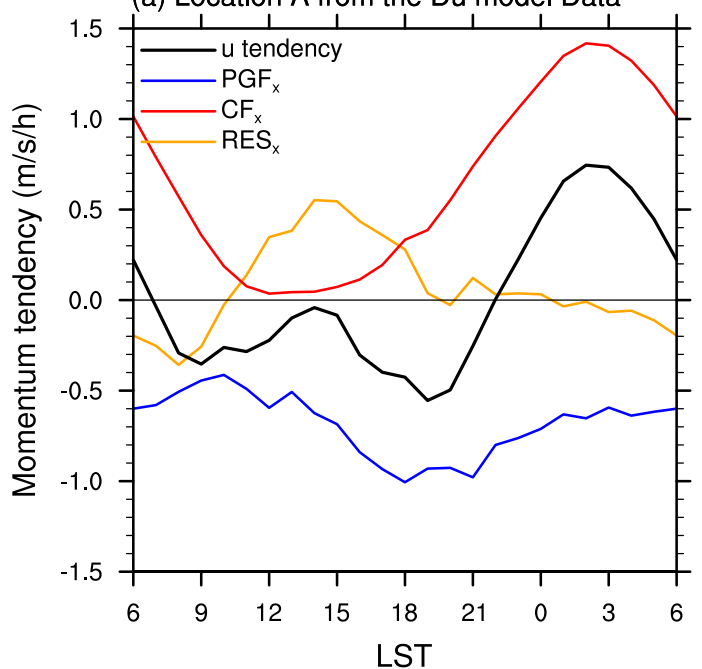

(c) Location A from the simple 1D model

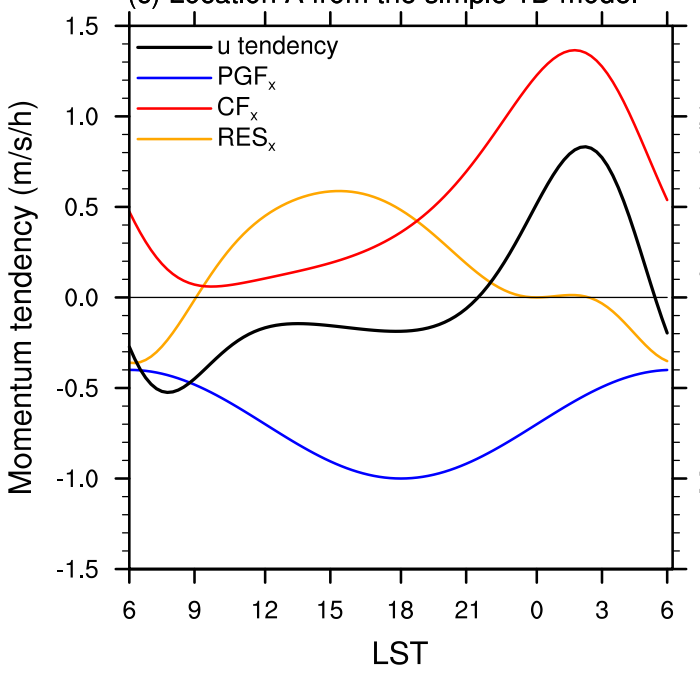

(b) Location A from the Du model data

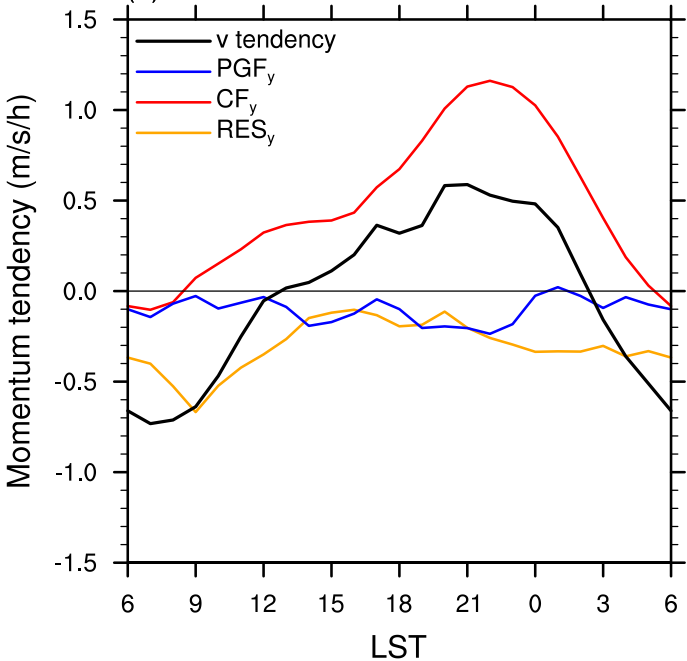

(d) Location A from the simple 1D model

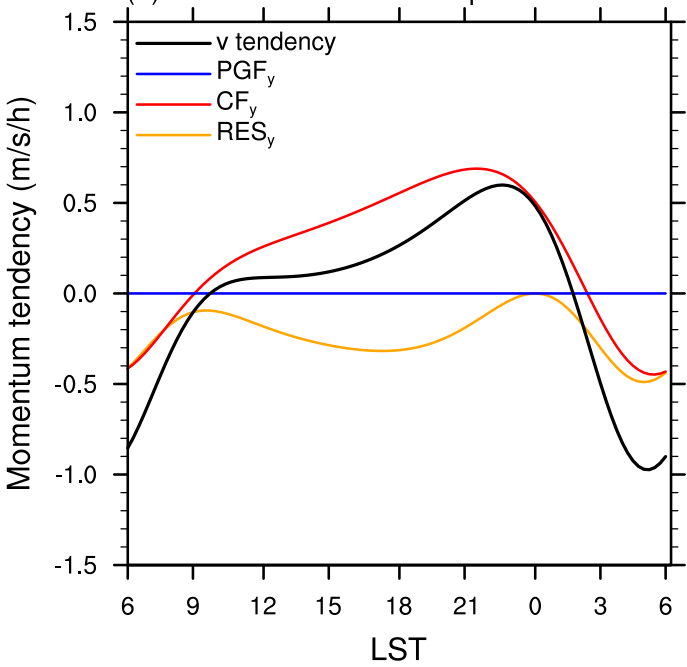

FIG. 4. Diurnal variation of the individual terms in the horizontal momentum equation in the (a) $x$ and (b) $y$ directions at the 950-hPa height at location A from the Du model data and (c),(d) the corresponding sets of terms from the simple $1 \mathrm{D}$ model.

1900 LST in the velocity curves is an artifact of the daily reinitialization method (Du et al. 2014); a dashed line that follows the general trend of the oscillation is added to give a more reliable estimate of the time of $u_{\min }$.

Finally, we compare the two low-latitude locations $C$ and D (Fig. 1b). Figure $2 \mathrm{~d}$ shows that the amplitude of diurnal wind for location $\mathrm{D}$ at the southernmost location of our domain (South China Sea) is notably weaker than it is that at location C (Fig. 2c), and the diurnal variation of the wind at location $\mathrm{D}$ is more complicated including an apparent semidiurnal component. At this location there is not just a diurnally varying pressure gradient in the $x$ direction but also a nonnegligible semidiurnal variation of the pressure gradient in the $y$ direction (blue lines in Figs. 7a and 7b).
Table 1 summarizes the important characteristics of the diurnal winds for locations A-D.

To examine the statistical significance of the timemean diurnal wind variations at locations A-D, Fig. 3 shows the interannual variability (for the analysis period 2006-11) of the diurnal winds in June. Generally, the diurnal winds every year exhibit similar features, which are discussed above. Note that the interannual variability for location $\mathrm{C}$ is larger than for the other locations (Fig. 3c); this larger variability is due to the greater variability of the mei-yu front in that area (Kosaka et al. 2011). We believe that the 6-yr average shown in Fig. 2 filters such planetary- or synoptic-scale variability at location $\mathrm{C}$ and thus is more representative of the typical local diurnal thermally driven circulation. 
(a) Location B from the Du model Data

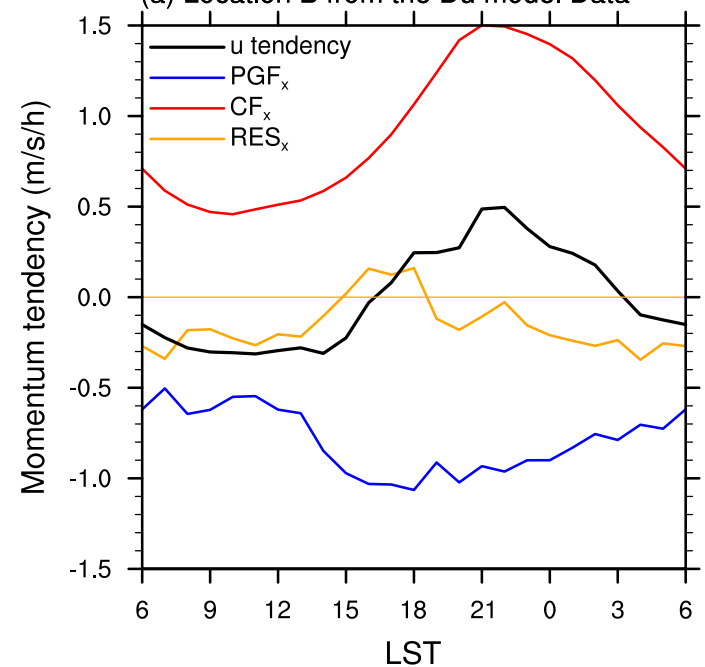

(c) Location B from the simple 1D model

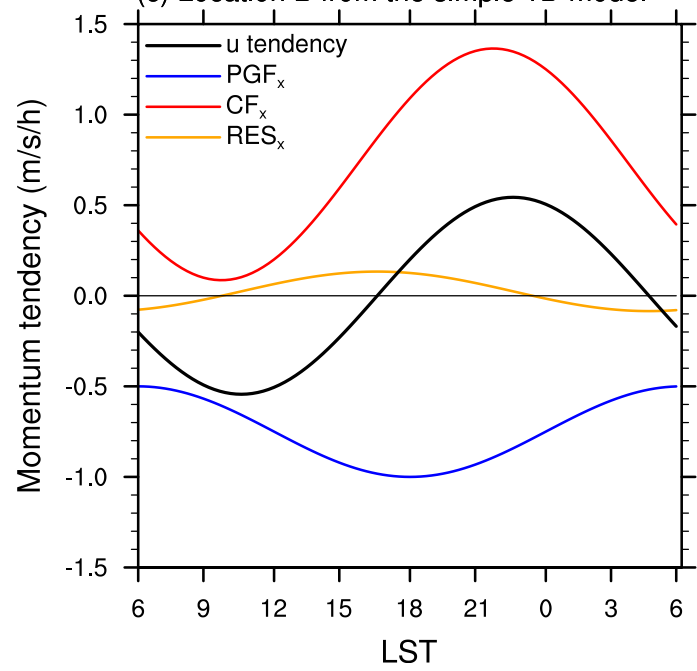

(b) Location B from the Du model Data

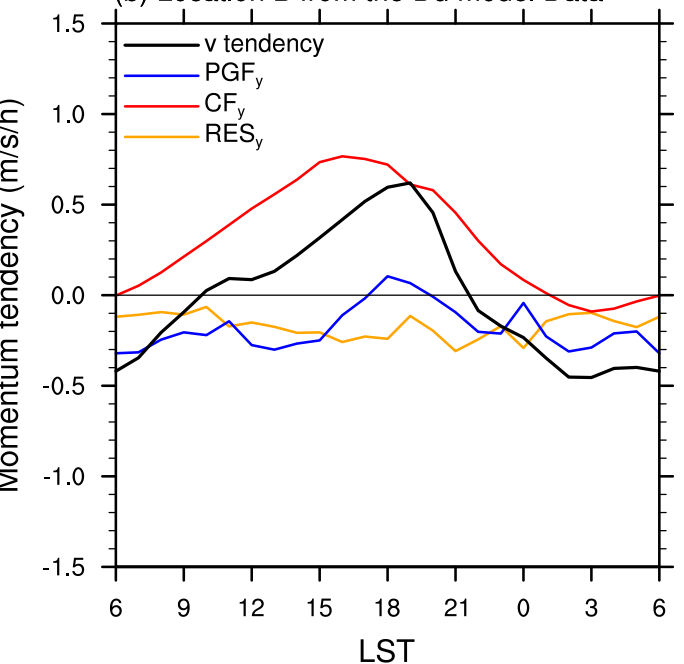

(d) Location B from the simple 1D model

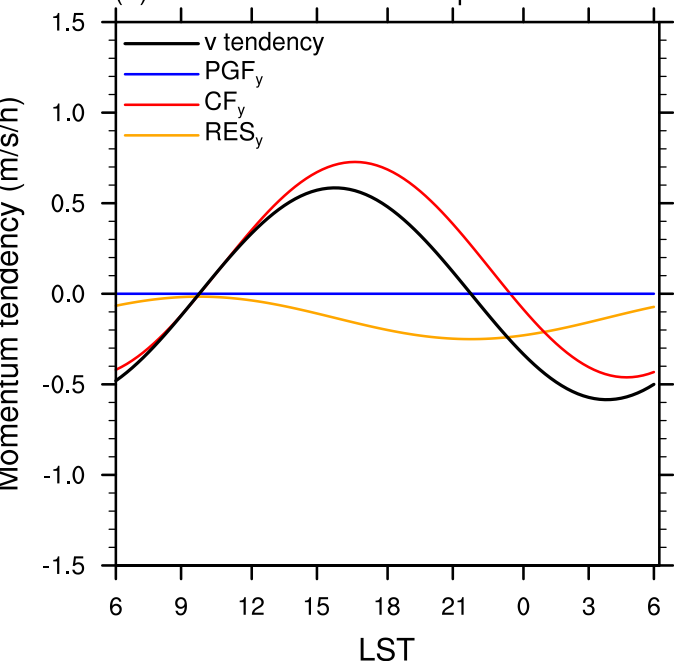

FIG. 5. As in Fig. 4, but at location B.

\section{Analysis of the diurnal winds}

We examined the differences in diurnal winds at different locations of eastern China in the previous section. In this section we seek to explain these differences with a simple 1D model.

\section{a. Comparison of the diurnal winds at locations $A$ and $B$}

The latitudes of location A $\left(35^{\circ} \mathrm{N}\right)$ and location $\mathrm{B}$ $\left(33^{\circ} \mathrm{N}\right)$ are similar (Fig. $1 \mathrm{~b}$ and Table 1). Locations A and $\mathrm{B}$ are influenced by the mountain-valley and landsea thermal contrasts, respectively, thus their diurnal variations of pressure gradient are similar (cf. blue lines in Figs. 4a,b and 5a,b). We hypothesize that the difference in the diurnal wind variation between locations $\mathrm{A}$ and $\mathrm{B}$ is because $\mathrm{A}$ is over the land whereas $\mathrm{B}$ is over the ocean. Over land, because of the significant difference of eddy viscosity between daytime and nighttime, the Blackadar mechanism should be taken into consideration in addition to the Holton (diurnal thermal forcing) mechanism. However, over the ocean where vertical mixing is small and has a weak diurnal cycle, only the Holton mechanism should play an important role in the diurnal winds.

Based on the diurnal variations of pressure gradient from the $\mathrm{Du}$ model data, we fit by trial and error $-(1 / \rho)(\partial P / \partial x)=-0.7+0.3 \cos \omega t$ for location A (blue line in Fig. 4c) and $-(1 / \rho)(\partial P / \partial x)=-0.75+0.25 \cos \omega t$ for location B (blue line in Figs. 5c) in the simple 1D model. Over land, the friction coefficient has a strong diurnal variation (because turbulent mixing is strong in the daytime and weak during the nighttime), while the friction coefficient over the ocean has only a weak 
(a) Location $\mathrm{C}$ from the Du model Data

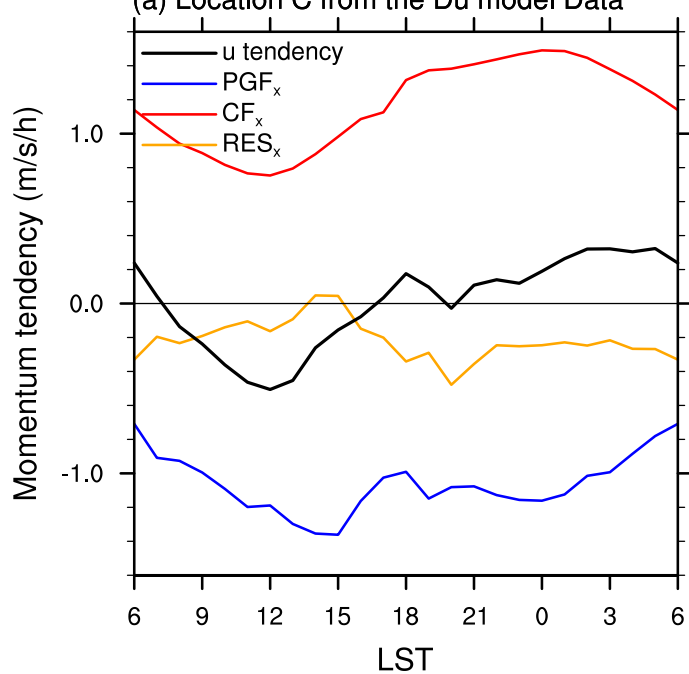

(c) Location $\mathrm{C}$ from the simple 1D model

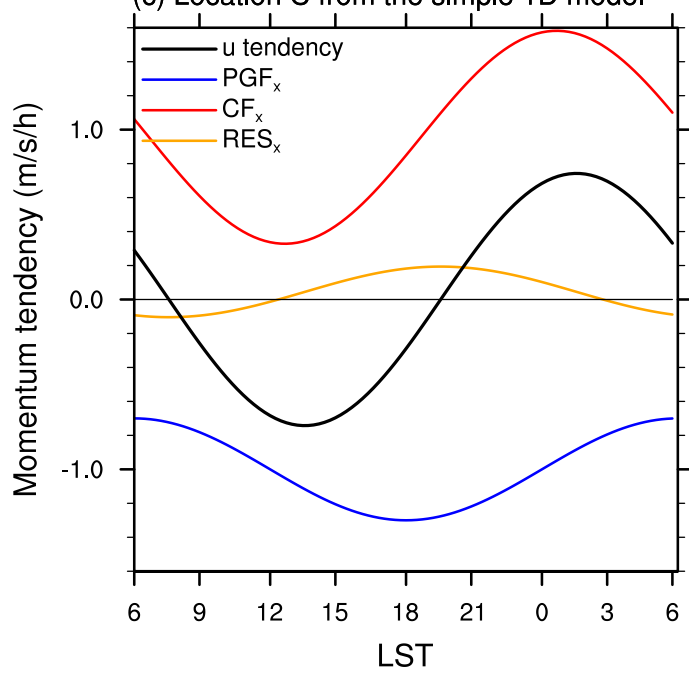

(b) Location C from the Du model Data

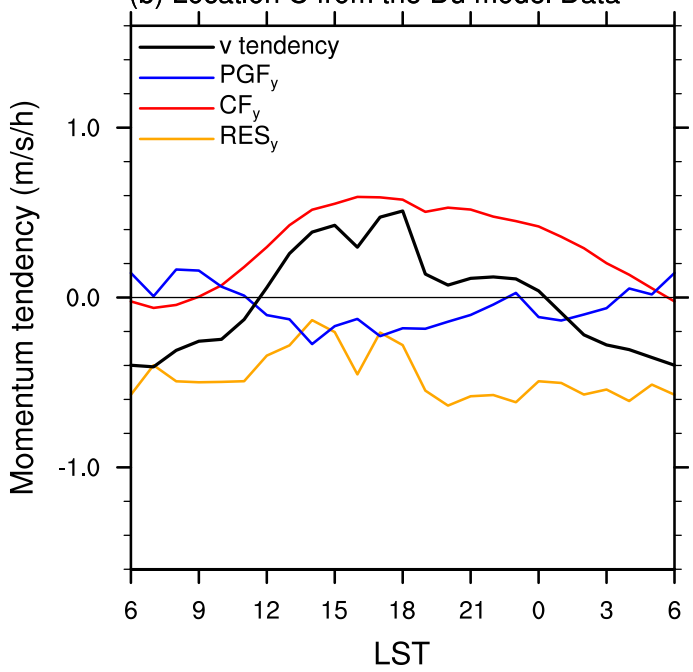

(d) Location $\mathrm{C}$ from the simple 1D model

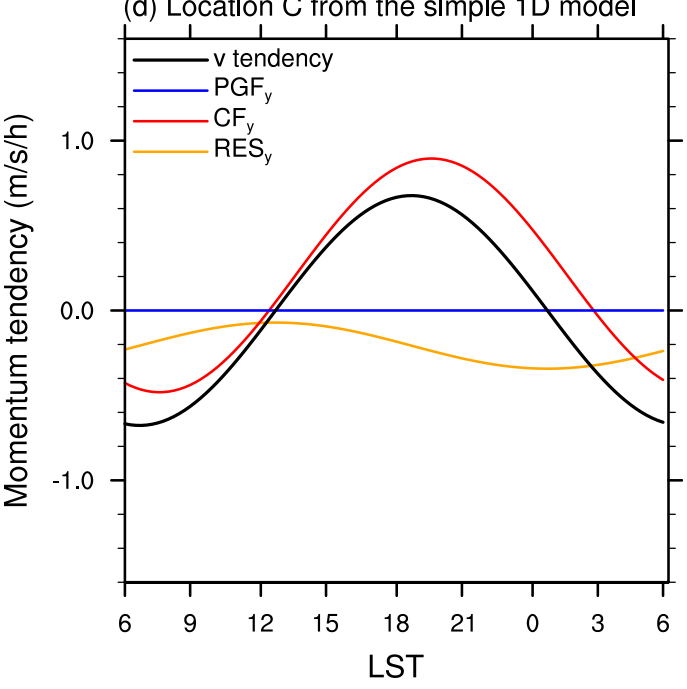

FIG. 6. As in Fig. 4, but at location C.

diurnal variation, thus the friction coefficients are set to $\alpha=[1+\sin (\omega t)] \omega$ for location A and $\alpha=0.2 \omega$ for location B (Jiang et al. 2007; Du and Rotunno 2014). Under this parameter setting, the magnitude of friction term from the Du model data and simple Du-Rotunno 1D model are well matched (Figs. 4-5). The analyses of the simple model velocity are shown in Figs. $2 \mathrm{e}$ and $2 \mathrm{f}$ and, for the individual terms in the horizontal momentum equation, in Figs. $4 \mathrm{c}$ and $4 \mathrm{~d}$ for location A and Figs. 5c and $5 \mathrm{~d}$ for location B. As shown in Figs. 2e and 2f, $v_{\max }$ at location A indeed occurs later than location B $(\sim 0200$ versus $\sim 2200 \mathrm{LST}$ ), which is similar to the Du model data (Figs. 2a and 2b) and in addition is consistent with the theory of Du and Rotunno (2014). Each individual term in the horizontal momentum equations in the simple model is similar to those from the Du model data (cf. Figs. 4a,b and $4 \mathrm{c}, \mathrm{d}$ for location A and Figs. 5a,b and 5c,d for location B) including tendency, pressure gradient force, Coriolis force, and friction (the horizontal advection terms are small and thus not shown). Du and Rotunno (2014) suggested that $v_{\max }$ for the combined mechanisms (diurnal thermal forcing, diurnally varying friction coefficient) occurs later than the time that it would occur with the pure Holton mechanism (diurnal thermal forcing, constant friction coefficient). We believe that the present comparison using a complex mesoscale model and a simple theory of the diurnal wind variation at locations $\mathrm{A}$ and $\mathrm{B}$ in eastern China clarifies the role of each mechanism in producing these observed diurnal winds.

\section{b. Comparison of the diurnal winds at locations $B$ and $C$}

Both locations $\mathrm{B}$ and $\mathrm{C}$ are over the ocean and near the coastline, but location $\mathrm{B}$ is north of $30^{\circ} \mathrm{N}$ while 
(a) Location D from the Du model Data

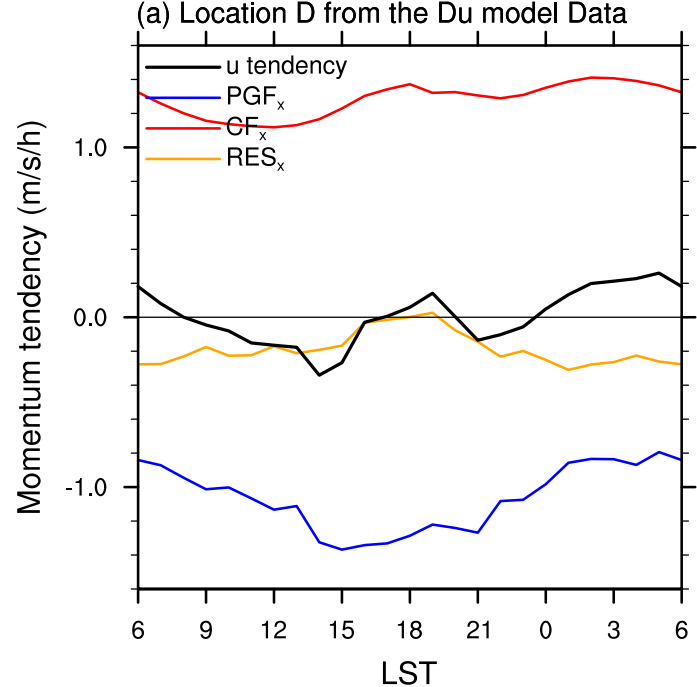

(c) Location $\mathrm{D}$ from the simple 1D model

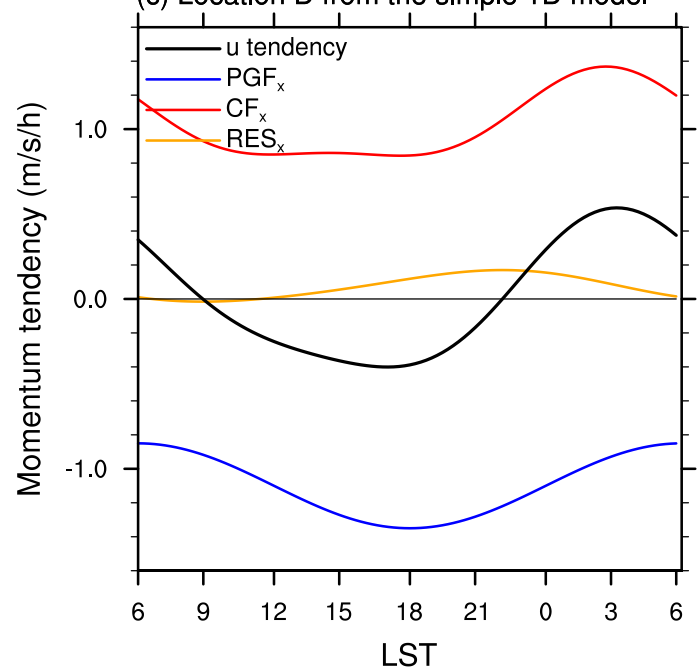

(b) Location D from the Du model Data

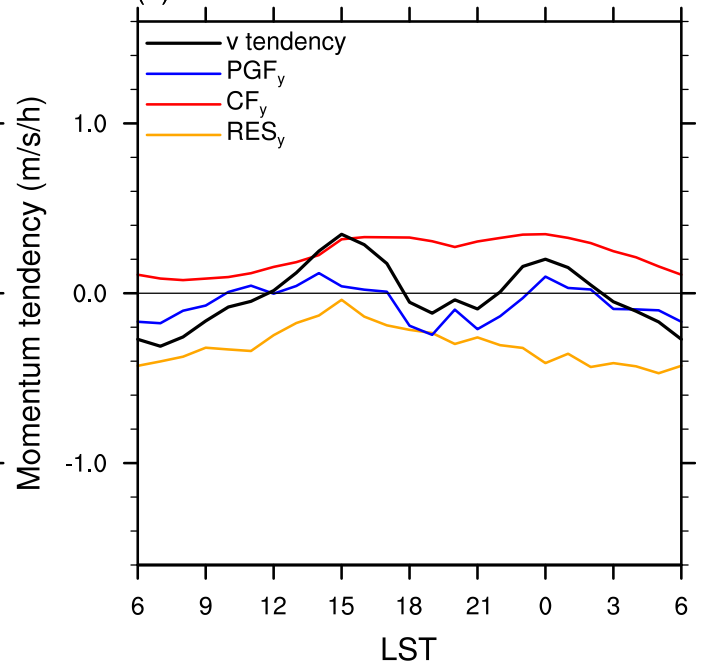

(d) Location D from the simple 1D model

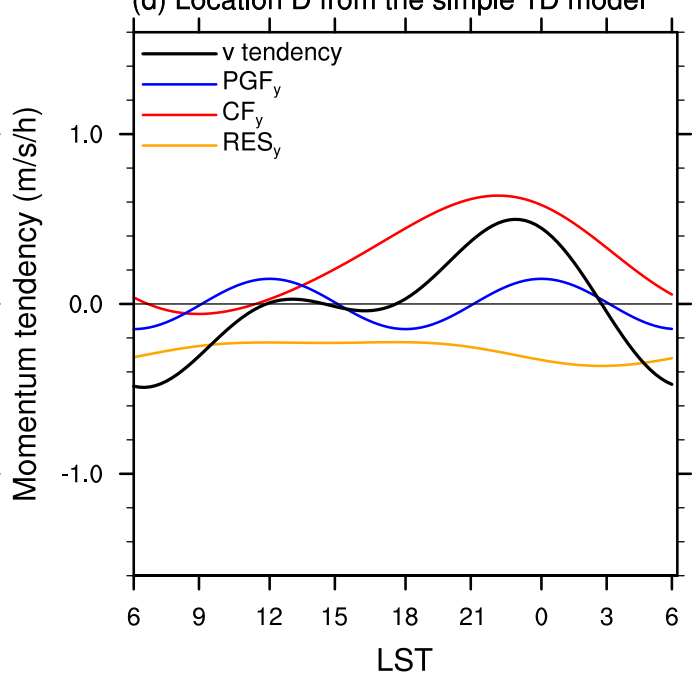

FIG. 7. As in Fig. 4, but at location D.

location $\mathrm{C}$ is south of $30^{\circ} \mathrm{N}$. The simple $1 \mathrm{D}$ model only including the Holton mechanism is applied. Constant friction coefficients $\left(\alpha_{0}=0.2 \omega\right)$ are set for both locations $\mathrm{B}$ and $\mathrm{C}$. We found that $v_{\max }$ at location B occurs earlier than at location $\mathrm{C}$ in the simple model owing to the different latitudes (cf. Figs. $2 \mathrm{f}$ and $2 \mathrm{~g}$ ), similar to the results from the Du model data (cf. Figs. $2 b$ and $2 c$ ).

The basic physics behind this phase difference is described in detail in the appendix. Here we consider a brief description starting with the analytical solution for the pure Holton mechanism (Du and Rotunno 2014) with, for simplicity, zero mean pressure gradient $(\bar{F}=0)$. Under the latter condition, their (3.3) becomes

$$
\begin{aligned}
& \tilde{v}=-\frac{\hat{\varepsilon} a}{\sqrt{\left(a^{2}+b_{0}^{2}-1\right)^{2}+4 b_{0}^{2}}} \sin (\tau+\psi), \text { where } \\
& \psi=\tan ^{-1}\left(\frac{a^{2}+b_{0}^{2}-1}{2 b_{0}}\right),
\end{aligned}
$$

TABLE 1. Locations, types of lower surface, and diurnal winds at the four locations A-D.

\begin{tabular}{cccccc}
\hline \hline Location & Lat $\left({ }^{\circ} \mathrm{N}\right)$ & Lon $\left({ }^{\circ} \mathrm{E}\right)$ & Type of lower surface & Time for $v_{\max }(\mathrm{LST})$ & Amplitude of $\left.v(\mathrm{~m} \mathrm{~s})^{-1}\right)$ \\
\hline $\mathrm{A}$ & 35 & 115.5 & Land & 0200 & 2.5 \\
$\mathrm{~B}$ & 33 & 121.5 & Ocean & 2100 & 3 \\
$\mathrm{C}$ & 27.5 & 121.0 & Ocean & 0100 & 1.5 \\
$\mathrm{D}$ & 22 & 115.0 & Ocean & 0200 & 0.9 \\
\hline
\end{tabular}




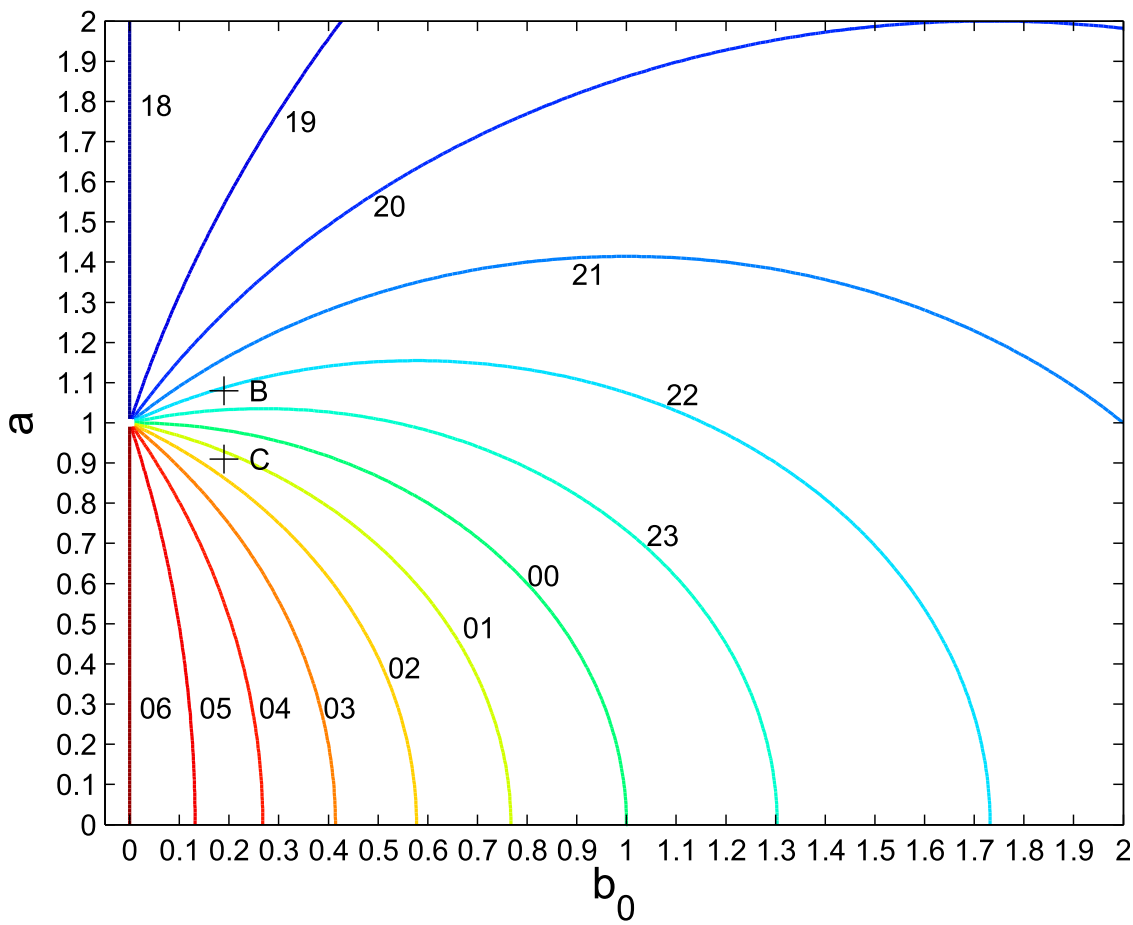

FIG. 8. The time of $v_{\max }$ (LST) as a function of $a$ (latitude) and $b_{0}$ (friction coefficient). The crosses show locations $\mathrm{B}$ and $\mathrm{C}$ with different latitudes and the same $b_{0}=0.2$.

where $\tilde{v}=v \omega / \hat{F}, a=f / \omega, \quad b_{0}=\alpha_{0} / \omega, \tau=\omega t$, and $\hat{\varepsilon}=$ $\hat{F} /(|\bar{F}|+|\hat{F}|)=1$ [see Du and Rotunno (2014) for details]. Figure 8 is a contour plot of the time of $v_{\max }$ as a function of $a$ and $b_{0}$; for $b_{0} \ll 1$, Fig. 8 shows that $v_{\max }$ occurs at sunset for $a>1$ (latitudes greater than $30^{\circ} \mathrm{N}$ ) whereas for $a<1, v_{\max }$ occurs at sunrise. Considering the effects of friction $\left(b_{0}>0\right)$, Fig. 8 shows $v_{\max }$ for $a>1$ occurs later than sunset whereas $v_{\max }$ for $a<1$ occurs earlier than sunrise. So, for example, at $b_{0}=0.2$ and at the latitudes of locations $\mathrm{B}$ and $\mathrm{C}$ (marked by the crosses), $v_{\max }$ for the latitude of $\mathrm{B}$ occurs at around 2200 LST whereas, for the latitude of location C, $v_{\max }$ occurs at about 0100 LST. Hence the latitudinal difference in the time of $v_{\max }$ drops from $12 \mathrm{~h}$ to approximately $3 \mathrm{~h}$ considering the effects of friction as estimated here. Finally, note that for very large friction the time of $v_{\max }$ becomes nearly independent of latitude.

\section{c. Comparison of the diurnal winds at locations $C$ and $D$}

Locations $\mathrm{C}$ and $\mathrm{D}$ are both south of $30^{\circ} \mathrm{N}$. Generally, the amplitude of the diurnal wind at location $\mathrm{D}$ $\left(22^{\circ} \mathrm{N}\right)$ is weaker than at location $\mathrm{C}\left(27.5^{\circ} \mathrm{N}\right)$ (cf. Figs. $2 \mathrm{c}$ and $2 \mathrm{~d}$ ). This characteristic is also successfully captured by the simple 1D model (Figs. $2 \mathrm{~g}$ and $2 \mathrm{~h}$ ).
From analytical solutions [see (4.1)], we know that the amplitude of the diurnal variation of $v$, $\hat{\varepsilon} a / \sqrt{\left(a^{2}+b_{0}^{2}-1\right)^{2}+4 b_{0}^{2}}$, decreases with decreasing $a$ (decreasing latitude), when $a<1$ (latitude less than $30^{\circ} \mathrm{N}$ ). The ratio of amplitude of diurnal $v$-component wind at $\mathrm{C}$ to $\mathrm{D}$ is around 1.68 based on the simple model, which is consistent with the Du model data $\left(1.5 \mathrm{~m} \mathrm{~s}^{-1} / 0.9 \mathrm{~m} \mathrm{~s}^{-1} \simeq 1.67\right)$. The amplitude of the diurnal variation of $u$ has the same trend [see (3.2) of Du and Rotunno (2014)].

Because of the weak local diurnal variation at location $\mathrm{D}$, the large-scale diurnal variation or semidiurnal variation becomes significant (Huang et al. 2010). Hence the diurnal variation at location $\mathrm{D}$ is more complicated with a nonnegligible semidiurnal variation of the pressure gradient in the $y$ direction. To better reproduce this complicated diurnal variation in the simple 1D model, we introduce a pressure gradient term in the $y$ direction $-(1 / \rho)(\partial P / \partial y)$ into $(2.6)$ and specify the term as $-(1 / \rho)(\partial P / \partial x)=-0.2 \cos 2 \omega t$ following Fig. $7 b$. The diurnal winds are obtained from the simple model (Fig. 2h), which includes weak semidiurnal variations. The double maxima of $v$ (late afternoon and night) can be roughly reproduced in the simple model similar to the results from the Du model data (Fig. 2d), though the late afternoon peak is much smaller 
than that of the Du model data. Because of the limitations of the simple 1D difficult, it is hard for it to replicate the complicated variation in phase and amplitude at location D.

\section{Summary}

Using long-term (June 2006-11) hourly high-resolution model data $(9-\mathrm{km}$ horizontal resolution and 40 vertical levels) simulated with a mesoscale model (WRF) from 12- to 36-h simulations of each day (Du et al. 2014), we study the low-level diurnal winds at different locations (locations A-D in Fig. 1b) in eastern China and compare their differences. A simple 1D model proposed by Du and Rotunno (2014) is used to explain the important characteristics of the WRF-simulated diurnal winds.

In northeastern China, at similar latitudes, the maximum velocity parallel to the coastline over the ocean (location B, 2100 LST) occurs earlier than the maximum velocity parallel to mountains over land (location A, 0200 LST). The simple 1D model with a sinusoidal diurnally varying friction coefficient or constant friction coefficient can reproduce the phase difference in the oscillations between locations $\mathrm{A}$ and $\mathrm{B}$, which suggests that the well-known Blackadar effect plays a significant role in determining the diurnal winds over land at location $\mathrm{A}$.

Off the eastern coast of China, the maximum velocity parallel to the coastline at the higher latitude (location $\mathrm{B}, 33^{\circ} \mathrm{N}$ ) occurs earlier than that at the lower latitude (location $\mathrm{C}, 27.5^{\circ} \mathrm{N}$ ). Based on our simple $1 \mathrm{D}$ model, we expect land-sea breezes to have very different phases with respect to the diurnal pressure gradient oscillation depending on whether the latitude is greater than or less than $30^{\circ} \mathrm{N}$. For zero friction coefficient, $v_{\max }$ (the maximum wind perpendicular to the pressure gradient) occurs at sunset for $a>1$ (latitudes greater than $30^{\circ} \mathrm{N}$ ) whereas for $a<1, v_{\max }$ occurs at sunrise, which implies a 12 -h phase difference between $v_{\max }$ at latitudes greater than and less than $30^{\circ} \mathrm{N}$; however, considering the effects of friction $\left(b_{0}>0\right), v_{\max }$ for $a>1$ occurs later than sunset while $v_{\max }$ for $a<1$ occurs earlier than sunrise. Hence the latitudinal difference (locations B and C) in the time of $v_{\max }$ decreases from 12 to approximately $3 \mathrm{~h}$ with our estimated friction coefficient and is consistent with results from Du model data. The amplitude of the diurnal wind off the southern coast (location $\mathrm{D}, 22^{\circ} \mathrm{N}$ ) is much weaker than that off the eastern coast (location $\mathrm{C}, 27.5^{\circ} \mathrm{N}$ ), which is also consistent with the latitudinal dependence expected from the simple 1D model.

Generally, the simple 1D model, including both diurnal thermal forcing and diurnally varying boundary layer friction, can roughly reproduce these WRF-simulated diurnal winds in eastern China. The latitudes and types of lower surface are important factors for understanding the phase and amplitude of these diurnal winds. However, the simple 1D model has more difficulty in replicating the diurnal cycle of winds at the most southern latitude (location D) where the pressure field exhibits a more complicated diurnal variation. Many other factors (e.g., steering level flow, latent heating, terrain effects, large-scale variability, variability of boundary layer height) not included in the simple 1D model are needed to more fully explain the complex threedimensional circulations contained in the data.

Acknowledgments. This study is supported by the Chinese 973 Program 2013CB430104 and the Chinese National Science Foundation under Grants 40921160380 , 4141101075, and 41330421. The authors gratefully acknowledge financial support from the China Scholarship Council. The authors are thankful to Peggy LeMone and Stan Trier for internal reviews and three anonymous reviewers for their valuable comments.

\section{APPENDIX}

\section{Explanation of (4.1)}

To illustrate the basic physics of phase differences in the $1 \mathrm{D}$ model, we reconsider the analytical solution for the pure Holton (land-sea-breeze) mechanism with, for simplicity, zero mean pressure gradient and a simple diurnally periodic forcing; under the latter condition, (2.5) and (2.6) become, respectively,

$$
\begin{aligned}
& \frac{\partial u}{\partial t}-f v=\hat{F} e^{-i \omega t}-\alpha u \quad \text { and } \\
& \frac{\partial v}{\partial t}+f u=-\alpha v .
\end{aligned}
$$

For real and positive $\hat{F}$, the forcing function in (A.1) describes a pressure gradient force that is a positive maximum at $t=0$ ("sunrise" or 0600 LST) and a negative minimum at $\omega t=\pi$ ("sunset" or 1800 LST), corresponding to the situation with the land to the west and ocean to the east, such as we have in the present study. Periodic solutions to (A.1) and (A.2) may be found in the form

$$
(u, v)=(\hat{u}, \hat{v}) e^{-i \omega t},
$$

where the coefficients of the exponential may be complex and thereby indicate the phase of the velocity components with respect to the forcing. Inserting (A.3) into (A.1) and (A.2) gives the solutions 


$$
\begin{aligned}
& \hat{u}=\frac{(-i \omega+\alpha) \hat{F}}{f^{2}+(-i \omega+\alpha)^{2}} \quad \text { and } \\
& \hat{v}=\frac{-f \hat{F}}{f^{2}+(-i \omega+\alpha)^{2}} .
\end{aligned}
$$

The simplest example is the case with both zero Coriolis force and zero friction $(f=\alpha=0)$; in this case, (A.4a) gives $\hat{u}=i(\hat{F} / \omega)$, indicating that the cross-coast velocity lags the pressure gradient forcing by $\pi / 2(6 \mathrm{~h})$. Including the Coriolis force changes the phase relation between the cross-coast velocity and pressure gradient since now (A.1) and (A.3) give $\hat{u}-i(f / \omega) \hat{v}=i(\hat{F} / \omega)$. Combining the latter with the $v$ equation, $\hat{v}=-i(f / \omega) \hat{u}$, gives the frictionless forms of (A.4a) and (A.4b):

$$
\begin{aligned}
& \hat{u}=\frac{i \omega \hat{F}}{\omega^{2}-f^{2}} \text { and } \\
& \hat{v}=\frac{f \hat{F}}{\omega^{2}-f^{2}} .
\end{aligned}
$$

Equation (A.5a) indicates that the cross-coast velocity can either lag or lead the pressure gradient by $\pi / 2$ depending on whether $f$ is less than or greater than $\omega$ (latitudes less than or greater than $30^{\circ}$ ). Since $\hat{v}=-i(f / \omega) \hat{u}$, the Coriolis force acts to rotate the cross-coast velocity to the along-coast component such that the latter always leads the cross-coast velocity by $\pi / 2$. These considerations imply the following: for latitudes less than $30^{\circ}$, the cross-coast velocity has a negative minimum (i.e., a sea breeze) at 0000 LST (midnight), followed by an along-coast velocity maximum (i.e., the jet) $6 \mathrm{~h}$ later at 0600 LST (sunrise); for latitudes greater than $30^{\circ}$, the sea breeze occurs at 1200 LST (noon) followed $6 \mathrm{~h}$ later by the jet at 1800 LST.

Exactly at the latitude of $30^{\circ}$, (A.5) is singular since the forcing frequency equals the natural frequency of the system. To resolve the singularity, friction must be considered and the inclusion of friction has a fundamental influence on the phase relations among the variables. Again starting with the simple example of zero Coriolis force, (A.1) and (A.3) give $\hat{u}=\left(\omega^{2}+\alpha^{2}\right)^{-1 / 2} \hat{F} e^{i \tan ^{-1}(\omega / \alpha)}$, which shows that friction reduces the lag of the crosscoast velocity with respect to the forcing from $\pi / 2$ to 0 for increasing $\alpha$. When both the Coriolis force and frictional effects are included, the situation becomes more complicated since friction has a direct effect of the cross-coast momentum equation [see (A.1)] but also an indirect effect through its influence on the Coriolis term by virtue of the along-coast velocity equation [see (A2)].
We focus here on (A.4b) as it is most directly applicable to the present discussion of the timing of the along-coast wind maximum. Equation (A.4b) may be written as

$$
\hat{v}=\frac{f}{\sqrt{\left(f^{2}-\omega^{2}+\alpha^{2}\right)^{2}+4 \alpha^{2} \omega^{2}}} e^{-i \chi} \hat{F},
$$

where

$$
\begin{aligned}
\chi & =\frac{\pi}{2}+\tan ^{-1}\left(\frac{f^{2}-\omega^{2}+\alpha^{2}}{2 \alpha \omega}\right) \\
& =\frac{\pi}{2}+\tan ^{-1}\left(\frac{a^{2}-1+b^{2}}{2 b}\right)
\end{aligned}
$$

which gives the phase lead of $v$ with respect to $F$; the second member of (A.7) uses the nondimensionalizations $a=f / \omega$ and $b=\alpha / \omega$ in Du and Rotunno (2014). Equation (A.6) is nondimensionalized (using $\hat{\varepsilon}=\hat{F} /(|\bar{F}|+|\hat{F}|)=1$, $\tilde{v}=v \omega / \hat{F}=\hat{v} \omega e^{-i \omega t} / \hat{F}$, and $\left.\tau=\omega t\right)$ and becomes

$$
\tilde{v}=\frac{\hat{\varepsilon} a}{\sqrt{\left(a^{2}+b^{2}-1\right)^{2}+4 b^{2}}} \cos (\tau+\chi),
$$

which is consistent with (4.1).

For $b \ll 1$, (A.7) gives $\chi=\pi$ for $a>1$ or $\chi=0$ for $a<1$; thus, (A.6) and (A.7) recover the results from (A.5b). An important feature of this equation is that $\chi(b)$ monotonically increases from 0 to $\pi$ for $a<1$; however, for $a>1, \chi(b)=\pi$ for $b \ll 1$ or $b \gg 1$ but has a minimum at an intermediate value. The implication is that for latitudes greater than $30^{\circ}$, the along-coast maximum that occurs at sunset for the frictionless case can occur later with small values of friction. For latitudes less than $30^{\circ}$, monotonically increasing $\chi(b)$ implies that the along-coast maximum occurs earlier and earlier until it reaches sunset of the previous day. Figure 8 is a contour plot showing the time of maximum along-coast flow as function of friction and latitude parameters and is consistent with the foregoing discussion.

\section{REFERENCES}

Blackadar, A. K., 1957: Boundary layer wind maxima and their significance for the growth of nocturnal inversions. Bull. Amer. Meteor. Soc., 38, 283-290.

Bonner, W. D., 1968: Climatology of the low level jet. Mon. Wea. Rev., 96, 833-850, doi:10.1175/1520-0493(1968)096<0833 COTLLJ $>2.0 . \mathrm{CO} ; 2$.

, and J. Paegle, 1970: Diurnal variations in boundary layer winds over the south-central United States in summer. Mon. Wea. Rev., 98, 735-744, doi:10.1175/1520-0493(1970)098<0735: DVIBLW $>2.3 . \mathrm{CO} ; 2$. 
Burk, S. D., and W. T. Thompson, 1996: The summertime lowlevel jet and marine boundary layer structure along the California coast. Mon. Wea. Rev., 124, 668-686, doi:10.1175/ 1520-0493(1996)124<0668:TSLLJA > 2.0.CO;2.

Colle, B. A., and D. R. Novak, 2010: The New York Bight jet: Climatology and dynamical evolution. Mon. Wea. Rev., 138, 2385-2404, doi:10.1175/2009MWR3231.1.

Drobinski, P., R. Rotunno, and T. Dubos, 2011: Linear theory of the sea breeze in a thermal wind. Quart. J. Roy. Meteor. Soc., 137, 1602-1609, doi:10.1002/qj.847.

Du, Y., and R. Rotunno, 2014: A simple analytical model of the nocturnal low-level jet over the Great Plains of the United States. J. Atmos. Sci., 71, 3674-3683, doi:10.1175/ JAS-D-14-0060.1.

—, Q. H. Zhang, Y. Yue, and Y. M. Yang, 2012: Characteristics of low-level jets in Shanghai during the 2008-2009 warm seasons as inferred from wind profiler radar data. J. Meteor. Soc. Japan, 90, 891-903, doi:10.2151/jmsj.2012-603.

— - — , Y. L. Chen, Y. Y. Zhao, and X. Wang, 2014: Numerical simulations of spatial distributions and diurnal variations of low-level jets in China during early summer. J. Climate, 27, 5747-5767, doi:10.1175/JCLI-D-13-00571.1.

Haurwitz, B., 1947: Comments on the sea-breeze circulation. J. Meteor., 4, 1-8, doi:10.1175/1520-0469(1947)004<0001: COTSBC $>2.0 . \mathrm{CO} ; 2$

Holton, J. R., 1967: The diurnal boundary layer wind oscillation above sloping terrain. Tellus, 19, 199-205, doi:10.1111/ j.2153-3490.1967.tb01473.x.

Huang, N. E., and S. S. Shen, Eds., 2005: Hilbert-Huang Transform and Its Applications. Interdisciplinary Mathematical Sciences, Vol. 5, World Scientific, 324 pp.

Huang, W. R., J. C. Chan, and S. Y. Wang, 2010: A planetary-scale land-sea breeze circulation in East Asia and the western North Pacific. Quart. J. Roy. Meteor. Soc., 136, 1543-1553, doi:10.1002/ qj.663.

Jiang, Q., S. Wang, and L. O'Neill, 2010: Some insights into the characteristics and dynamics of the Chilean low-level coastal jet. Mon. Wea. Rev., 138, 3185-3206, doi:10.1175/ 2010MWR3368.1.

Jiang, X., N. C. Lau, I. M. Held, and J. J. Ploshay, 2007: Mechanisms of the Great Plains low-level jet as simulated in an AGCM. J. Atmos. Sci., 64, 532-547, doi:10.1175/ JAS3847.1.

Kosaka, Y., S.-P. Xie, and H. Nakamura, 2011: Dynamics of interannual variability in summer precipitation over East Asia. J. Climate, 24, 5435-5453, doi:10.1175/2011JCLI4099.1.
Liu, H. B., L. J. Li, and B. Wang, 2012: Low-level jets over southeast China: The warm season climatology of the summer of 2003. Atmos. Oceanic Sci. Lett., 5, 394-400.

Paegle, J., and G. E. Rasch, 1973: Three-dimensional characteristics of diurnally varying boundary-layer flows. Mon. Wea. Rev., 101, 746756, doi:10.1175/1520-0493(1973)101<0746:TCODVB > 2.3.CO;2.

Parish, T. R., and L. D. Oolman, 2010: On the role of sloping terrain in the forcing of the Great Plains low-level jet. J. Atmos. Sci., 67, 2690-2699, doi:10.1175/2010JAS3368.1.

Rife, D. L., J. O. Pinto, A. J. Monaghan, C. A. Davis, and J. R. Hannan, 2010: Global distribution and characteristics of diurnally varying low-level jets. J. Climate, 23, 5041-5064, doi:10.1175/ 2010JCLI3514.1.

Rotunno, R., 1983: On the linear theory of the land and sea breeze. J. Atmos. Sci., 40, 1999-2009, doi:10.1175/1520-0469(1983)040<1999: OTLTOT $>2.0 . \mathrm{CO} ; 2$.

Schmidt, F. H., 1947: An elementary theory of the land- and sea-breeze circulation. J. Meteor., 4, 9-20, doi:10.1175/ 1520-0469(1947)004<0009:AETOTL>2.0.CO;2.

Skamarock, W. C., and J. B. Klemp, 2008: A time-split nonhydrostatic atmospheric model for weather research and forecasting applications. J. Comput. Phys., 227, 3465-3485, doi:10.1016/j.jcp.2007.01.037.

Stensrud, D. J., 1996: Importance of low-level jets to climate: A review. J. Climate, 9, 1698-1711, doi:10.1175/1520-0442(1996)009<1698: IOLLJT $>2.0 . \mathrm{CO} ; 2$.

Thorpe, A. J., and T. H. Guymer, 1977: The nocturnal jet. Quart. J. Roy. Meteor. Soc., 103, 633-653.

Wang, D., Y. Zhang, and A. Huang, 2013: Climatic features of the south-westerly low-level jet over southeast China and its association with precipitation over east China. Asia-Pac. J. Atmos. Sci., 49, 259-270, doi:10.1007/s13143-013-0025-y.

Wei, W., B. G. Wu, X. X. Ye, H. X. Wang, and H. S. Zhang, 2013: Characteristics and mechanisms of low-level jets in the Yangtze River Delta of China. Bound.-Layer Meteor., 149, 403-424, doi:10.1007/s10546-013-9852-8.

Whiteman, C. D., X. Bian, and S. Zhong, 1997: Low-level jet climatology from enhanced rawinsonde observations at a site in the southern Great Plains. J. Appl. Meteor., 36, 1363-1376, doi:10.1175/1520-0450(1997)036<1363:LLJCFE>2.0.CO;2.

Yu, R., J. Li, and H. Chen, 2009: Diurnal variation of surface wind over central eastern China. Climate Dyn., 33, 1089-1097, doi:10.1007/s00382-008-0478-3.

Zhang, D.-L., S.-L. Zhang, and S. J. Weaver, 2006: Low-level jets over the Mid-Atlantic states: Warm-season climatology and a case study. J. Appl. Meteor. Climatol., 45, 194-209, doi:10.1175/JAM2313.1. 